\title{
The Spatial Impact of Genetically Modified Crops.
}

By

Alistair Munro

Royal Holloway, University of London

Department of Economics, Royal Holloway, University of London,

Egham, TW20 0EX, UK

Email: Alistair.munro@rhul.ac.uk

* Acknowledgements.

I am grateful for comments from two anonymous referees and from the participants at the Biotechnology, Environmental Policy and Agriculture Workshop on the Management of the Impacts of Biotechnologies, Rome, May 2000, particularly Tim Swanson and Gardner Brown. 
Abstract.

Although genetically modified (GM) organisms have attracted a great deal of public attention, analysis of their economic impacts has been less common. It is, perhaps, spatial externalities where the divergence between efficient and unregulated outcomes is potentially largest, because the presence of transgenic crops may eliminate or severely reduce the planting of organic varieties and other crops where some consumers have a preference for non GM crops. This paper constructs a simple model of the possible spatial external effects of the introduction of transgenic varieties and considers some of the public policy options for regulating the divergence between market outcomes and the efficient allocation of resources to GM crops. It is shown that co-existence may be impossible without strong regulation on planting patterns.

Key words: Genetically modified organisms; spatial externality; optimal regulation. 


\section{Introduction}

This paper focuses on some of the spatial effects of transgenic crops, when some consumers at least have a preference for non-modified crops. Because pollen and seed from transgenic varieties may spread from the original site of planting to neighbouring fields and farms, there is the potential for a spatial external effect - an example of what is sometimes termed 'genetic pollution'. The major lessons of the paper are stark: first, even if a) many consumers are unwilling to buy genetically modified (GM) crops at any price and b) the degree to which GM crops affect non-modified variants is small, there may be no market equilibrium in which non-GM crops are grown. Secondly, market-based public policy instruments, such as a tax on GM varieties, may be only partially successful in achieving optimality - more dirigiste policies may be required to achieve efficiency.

There is a growing literature analysing the economics of transgenic technologies (e.g. Batie, 2003, Fulton and Giannakas, 2004, Sianesi and Ulph, 1998, Goeschl and Swanson, 2003, Munro, 2003, Nelson and Bullock, 2003). This literature has largely ignored the issue of spatial externalities despite its salience in popular discussion of GM technology. ${ }^{1}$ Belcher et al 2005, is a notable exception as it provides some interesting simulations of an agentbased model that illustrate the potential for GM crops to eliminate non-GM varieties. This

1 There have been several high-profile legal cases (e.g. Guardian, 2000), in which biotechnology companies have sued farmers who claimed not to have bought or sown the transgenic seed, but whose crops have displayed evidence of the resistance to a specific herbicide which characterises the GM product. The farmers' defence is that resistance is due to the spread of seed or cross-pollination from adjoining farms where the GM seed has been (legally) sown. 
paper (see also Munro, 2000) goes beyond Belcher et al in a number of ways. First, I provide an analytical model in which consumers and producers optimize within what is clearly an economic environment. Second, the model is used to identify the circumstances when the external effect of the new varieties (i.e. transgenic) eliminates production of existing varieties. Thirdly, the model is used to consider the welfare costs of the unregulated transgenic technology. Finally, and perhaps most importantly I consider formally some of the public policy implications of the models for the prudential regulation of transgenic technologies.

The plan of the paper is as follows: in the next section I give a brief overview of the evidence for spatial externalities in the context of GM crops. Section 3 provides a simple theoretical model which contrasts the social optimum outcome with the market equilibrium. Section four offers some illustrative simulations while in section five I consider the problem of optimal public policy instruments. Section six concludes the paper.

\section{Background.}

Much of the broad nature of transgenic technologies is now well-known (.e.g. Batie, 2003, Aslaksen and Myhr, 2007). For instance, with the Roundup Ready TM varieties developed by Monsanto, genes which confer resistance to Roundup ${ }^{\mathrm{TM}}$ (Monsanto's glyphosate herbicide) have been introduced into food crops. Compared to traditional varieties, the resulting plants have a higher tolerance for glyphosate which can therefore be used at higher than traditional doses to combat weed growth and also used at times in the growth cycle (such as after crop emergence) which would previously have been disastrous for yields.

The spread of crops and their genes out of the planted field into the general environment occurs through a number of routes including airborne and insect-borne pollen 
dispersal, as well as via seed loss during transit. As Rob Treu and Jean Emberlin, 2000, emphasise the degree to which the spread occurs depends on a variety of a factors, a number of which are specific to the crop and the locality in which it is grown. Meanwhile, the possibilities for the establishment of a feral population of the crop or for inter-breeding with wild relatives depends not only on the spread of pollen or seed, but also on the extent to which the crop is competitive in the wild, and on the genetic closeness and abundance of its relatives. As an example, oil seed rape (Brassica napus ssp. oleifera), has a number of close relatives growing wild, while other relatives are used as crops, including Brassica oleracea. (The wild plant is var. oleracea, cultivated varieties include cabbage, cauliflower, broccoli and Brussel sprouts.) In contrast, wheat has few potential partners for hybridisation and its self-fertilising nature means that what little pollen is produced is viable only for short periods of time.

The status of the debate on the issue of whether gene transfer represents an ecological or economic problem is exemplified by the lack of consensus on safe planting distances even at the official level. As an illustration, Table 1 shows the range of minimum planting distances between GM and non-GM varieties as recommended by member states in the European Union as of 2006. Even countries with access to shared scientific advice can therefore differ sharply on the issue. Meanwhile organic producers take a much stronger line: for instance the Soil Association, the principle certifier of organic produce in the UK, has set safe distances of 9600m (Soil Association, 1999) - higher than any of the figures in Table 1.

\section{[Table 1 about here]}

Beyond what might be termed the production externalities that would flow from the widespread transfer of resistance, there is, in addition, the issue of consumption externalities. Whatever the scientific facts about transgenic foods, reports of a price premium for non-GM 
soybeans, coupled with widespread efforts to introduce labelling schemes, suggest that many consumers perceive GM and non-GM foods as different and that some consumers are willing to pay extra to have food which is certified free of GM ingredients. For instance, Noussair et al, 2004, report that amongst French consumers, 35\% are unwilling to buy GM food, 23\% are indifferent about its provenance and $42 \%$ would buy GM if the price advantage was sufficient. However, in the absence of an effective and economical means of separating GM and nonGM varieties, fields infiltrated with a positive fraction of the GM variety will not reap the same price premium as crops guaranteed GM free. As a result, in a competitive market for foodstuffs, farms adjacent to farms where the GM variety is grown, producing the higher cost non-GM food, but compelled to sell it for the lower price of the GM variety are likely to face elimination from the market or be forced to switch to the GM variety. ${ }^{2}$ Potentially therefore co-existence of GM and non-GM varieties may not be possible within the same locality. It is this issue which is modelled in the next section.

\section{Modelling Spatial Externalities.}

To simplify the analysis we consider a rectangular-shaped spatial economy, the area of which represents the upper bound on the total amount of the crop which can be produced. I normalise the area of this rectangle to 1 and suppose its width to be w. Two varieties of the crop can be produced, one of which is genetically modified, ' $g$ ', and which is not - ' $n$ '. Let $c_{g}$ and $c_{n}$ be respectively, the unit cost of producing each type, with $c_{g}<c_{n}$. The corresponding prices are $\mathrm{p}_{\mathrm{g}}$ and $\mathrm{p}_{\mathrm{n}}$ and the quantities are $\mathrm{q}_{\mathrm{g}}$ and $\mathrm{q}_{\mathrm{n}}$. I suppose that each individual consumes

\footnotetext{
${ }^{2}$ This issue may be particularly acute for the organic sector, given its position on safe distances.
} 
only one variant, choosing between them on the basis of price and their 'distaste' for the genetically modified food. Specifically, let the indirect utility of the non-GM food be $\left(a-p_{n}\right)^{2}$ and let the indirect utility of the GM variant be $\left(\mathrm{a}-\theta-\mathrm{p}_{\mathrm{g}}\right)^{2}$ where $0 \leq \square \theta \leq \square$ a. Someone who does not care about the crop variant has a value of $\theta=0$, while someone who would never consume the GM food has a value of $\theta=a$. Normalise the marginal utility of income at 1 , so that individual demand is either $\left(a-p_{n}\right)$ if the non-GM product is chosen or $\left(a-\theta-p_{g}\right)$ if the consumer opts for the GM variety. Let the density function of consumers be $f$ with $F$ as the corresponding cumulative function. Finally, it will be useful to define $\Delta p=p_{n}-p_{g}$, as the price premium paid in the market place for the non-GM food.

In the absence of any spatial externalities and with perfect competition and a free choice of variant for both producer and consumer, one of four outcomes will occur in equilibrium:

Case 1. $\mathrm{p}_{\mathrm{g}}-\mathrm{c}_{\mathrm{g}}=\mathrm{p}_{\mathrm{n}}-\mathrm{c}_{\mathrm{n}}>0$ and $\mathrm{q}_{\mathrm{g}}+\mathrm{q}_{\mathrm{n}}=1$.

Case 2. $\mathrm{p}_{\mathrm{g}}-\mathrm{c}_{\mathrm{g}}=\mathrm{p}_{\mathrm{n}}-\mathrm{c}_{\mathrm{n}}=0$ and $\mathrm{q}_{\mathrm{g}}+\mathrm{q}_{\mathrm{n}} \leq 1$.

Case 3. $p_{g}-c_{g}>0 ; p_{g}-c_{g} \geq p_{n}-c_{n}$ and $q_{g}=1$.

Case 4. $\mathrm{p}_{\mathrm{n}}-\mathrm{c}_{\mathrm{n}}>0 ; \mathrm{p}_{\mathrm{n}}-\mathrm{c}_{\mathrm{n}} \geq \mathrm{p}_{\mathrm{g}}-\mathrm{c}_{\mathrm{g}}$ and $\mathrm{q}_{\mathrm{n}}=1$.

In case 1 all the land is planted and there are positive quantities of both crops in equilibrium and positive profits for farmers. In case 2 some land is not planted, while in cases 3 and 4 the planting of a single crop is most profitable. Case 1 occurs when $\theta^{\mathrm{m}}+1>\mathrm{c}_{\mathrm{n}}-\mathrm{c}_{\mathrm{g}}>\theta^{\mathrm{L}}-1$, where $\theta^{\mathrm{m}}$ is the mean value of $\theta$ and $\theta^{\mathrm{L}}$ is the lowest value of $\theta$ for which $\mathrm{f}(\theta)>0$. If there are some people who do not care about the source of the crop (i.e. $\theta^{\mathrm{L}}=0$ ), then the right hand side of this inequality is automatically satisfied and case 4 cannot occur.

Consider now the possibility of an external effect from the GM crop, in the sense that if the GM crop is grown at one site, all crops grown within a particular distance, $\mathrm{d}$, from the 
site are contaminated by GM varieties. I call this area the shadow of the GM crop. As a result, the consumer views all such crops as genetically modified and they therefore sell for $\mathrm{pg}_{\mathrm{g}}$. This is an extreme position in some ways, but it reflects the typical pattern of labelling regulations (in for instance Regulation (Ec) No 1830/2003 of the European Union) which are typically defined in terms of clear (but sometimes arbitrary) purity thresholds.

As we shall see below, provided $\mathrm{d}$ is small compared to the total area under cultivation, it has only a marginal effect on the optimal planting of the two varieties, but it may still have a sharp impact on the market equilibrium.

Let $\delta^{*}\left(\mathrm{q}_{\mathrm{n}}, \mathrm{q}_{\mathrm{g}}\right)$ be the minimum possible affected land given the area devoted to each of the two crops and let $\delta$ be the actual affected area. Within a rectangle of width $\mathrm{w}, \delta^{*}$ is a fairly straightforward function of the variables $\mathrm{q}_{\mathrm{n}}$ and $\mathrm{q}_{\mathrm{g}}$. If either variable is zero then $\delta^{*}$ is zero as it will be if $\mathrm{q}_{\mathrm{n}}+\mathrm{q}_{\mathrm{g}}<1$-wd (i.e. there is an area of unplanted land large enough to separate the two crops). If $\mathrm{q}_{\mathrm{n}}+\mathrm{q}_{\mathrm{g}}=1$, (i.e. case 1 ) then for sufficiently small values of one of these two variables the optimal pattern of cultivation is a quarter circle of the minority crop, centred on one of the corners of the rectangle. The majority crop then occupies the rest of the rectangle. For $1-\mathrm{w}^{2} / \pi>\mathrm{q}_{\mathrm{g}}>\mathrm{w}^{2} / \pi$ the optimal pattern involves a single linear boundary between the two crops, across the width of the rectangle. For the purposes of simplifying exposition, I shall call this situation the central case in what follows and focus on it. I do not claim that necessarily this is empirically the most important case, but the range of parameter values brings to the fore the policy dilemmas in a fairly straightforward manner.

In conventional fashion, the planner's problem is to maximize the sum of consumer and producer surplus, $\mathrm{W}$ :

$\mathrm{W}=$ Consumer surplus for GM purchasers + Consumer surplus for non-GM purchasers + producer surplus for GM producers + producer surplus for non-GM 
producers.

Planner's problems are often set in terms of quantities. To simplify understanding of the policy analysis which follows I use a mixture of prices (for consumers) and quantities (for producers) and suppose that the planner maximizes $\mathrm{W}$ subject to the constraints that supply be less than or equal to total land area, that demand equal the supply for each variant and that the shadow be no less than $\delta^{*}$. Thus the planner maximizes:

$$
\begin{aligned}
& \frac{1}{2} \int_{0}^{\Delta p}\left(a-\theta-p_{g}\right)\left(a-\theta+p_{g}\right) f d \theta+\frac{1}{2} \int_{\Delta p}^{a}\left(a-p_{n}\right)\left(a+p_{n}\right) f d \theta-c_{g} q_{q}-c_{n} q_{n}+\lambda\left(1-q_{n}-q_{g}\right) \\
& +\mu\left(\delta-\delta^{*}\left(q_{g}, q_{n}\right)\right)+\gamma_{1}\left(q_{g}+\delta-\int_{0}^{\Delta p}\left(a-\theta-p_{g}\right) f d \theta\right)+\gamma_{2}\left(q_{n}-\delta-\int_{\Delta p}^{a}\left(a-p_{n}\right) f d \theta\right)
\end{aligned}
$$

The first two terms in this expression represent the benefits of the two varieties, the third and fourth terms are the costs and $\lambda$ is the Lagrangean multiplier on the constraint that total production cannot exceed capacity. The next term represents the constraint that the area affected with GM cannot be smaller than $\delta^{*}$. Finally we have the two constraints that demand equals supply of the two types. Note the position of the ' $\delta$ ' entries in these two constraints: total production of the GM variety is lower than the total consumption because crops from an area $\delta$ of the non-GM variety are viewed by consumers as GM crops. Conversely, production of the non-GM variety is greater than consumption, by the amount $\delta$.

Optimizing with respect to $\mathrm{p}_{\mathrm{n}}, \mathrm{p}_{\mathrm{g}}, \mathrm{q}_{\mathrm{n}} \mathrm{q}_{\mathrm{g}}$ and $\delta$, first order conditions for optimality are,

$$
\begin{gathered}
-p_{n}(1-F(\Delta p))+\gamma_{2}(1-F(\Delta p))-\left(\gamma_{2}-\gamma_{1}-p_{n}+p_{g}\right) f(\Delta p)\left(a-p_{n}\right)=0 \\
-p_{g} F(\Delta p)+\gamma_{1} F(\Delta p)+\left(\gamma_{2}-\gamma_{1}-p_{n}-p_{g}\right) f(\Delta p)\left(a-p_{n}\right)=0 \\
-c_{n}-\lambda-\mu \delta_{2}^{*}+\gamma_{2}=0 \\
-c_{g}-\lambda-\mu \delta_{1}^{*}+\gamma_{1}=0
\end{gathered}
$$




$$
\mu+\gamma_{1}-\gamma_{2}=0
$$

The subscripts on $\delta^{*}$ represent the partial derivatives of that function. In addition there is the potentially relevant complementary slackness condition:

$$
\text { Either } 1=q_{n}+q_{g} \text { or } \lambda=0 \text {; }
$$

Solving the equations (2)-(7) leads to the same 4 cases as above. In particular, in the central case as defined above, where $\delta^{*}=\mathrm{wd}$, then $\delta^{*}{ }_{\mathrm{i}}=0$. As a result equations (2)-(3) are solved by setting $p_{g}=\gamma_{g}$ and $p_{n}=\gamma_{2}$. Using (4) and (5) we then get $\left(\gamma_{1}-\gamma_{2}\right)=\left(c_{n}-c_{g}\right)$ so that at the optimum $p_{n}-c_{n}=p_{g}-c_{g} \geq 0$.

Note that in the central case the first order conditions are independent of $\mathrm{d}$. It follows that the solution to the first order conditions is the same with and without the presence of the externality. The difference between the two worlds concerns the area affected by the externality which represents a fixed cost of having the GM variety. As a result for $\mathrm{d}>0$ the maximand is not globally concave. There are therefore two cases to consider. If $\mathrm{d}$ is large enough a corner solution is optimal: it will be optimal to ban the GM variety and allow only the non-GM variety to be sold. Conversely if the area $\delta^{*}(=\mathrm{dw})$ is small compared to the total area under cultivation, then the optimal consumption pattern will be identical to that which pertains in the absence of the external effect. That is, if $\left(\mathrm{q}^{*}, \mathrm{q}_{\mathrm{g}}{ }_{\mathrm{g}}\right)$ is the optimal mix of production in the absence of the external effect, then $\left(\mathrm{q}^{*}{ }_{\mathrm{n}}+\mathrm{dw}, \mathrm{q}^{*} \mathrm{~g}_{\mathrm{d}} \mathrm{dw}\right)$ will be optimal given the external effect, so that consumption is unchanged.

We now need to consider the market equilibrium: an outcome such that,

(a) given prices all consumers choose the type and quantity they prefer;

(b) given prices and the planting decisions at every other coordinate in the rectangle, planting (GM, non-GM or not planting at all) at a given coordinate maximizes profits. 
So, at each coordinate, a farmer chooses either not to plant, to plant the GM crop or to plant the non-GM crop. In fact no market equilibrium can occur that corresponds to the central case. We state this formally.

Proposition. There can be no market equilibrium in which all land is cultivated and both types co-exist.

Proof. Suppose that such an equilibrium exists. Since there is co-existence then $\mathrm{p}_{\mathrm{g}}$ $c_{\mathrm{g}}=\mathrm{p}_{\mathrm{n}}-\mathrm{c}_{\mathrm{n}}$. Since all land is cultivated there must be co-ordinates at which the non-GM crop is grown within a distance $\mathrm{d}$ of the GM crop. For a crop grown at such a coordinate the profit is $\mathrm{p}_{\mathrm{g}}-\mathrm{c}_{\mathrm{n}}$ per unit since the crop sells at the GM price. But $\mathrm{c}_{\mathrm{n}}>\mathrm{c}_{\mathrm{g}}$ so $\mathrm{p}_{\mathrm{g}}-\mathrm{c}_{\mathrm{n}}<\mathrm{p}_{\mathrm{g}}-\mathrm{c}_{\mathrm{g}}$. Hence the decision to grow the non-GM crop at such a co-ordinate cannot be profit-maximizing.

Note that this result is independent of the size of $d$, so that even if the externality is small (in the sense that $d$ is small), the market equilibrium and the social optimum may be fundamentally different.

More generally, the failure of co-existence of the crops when they must be grown adjacently means there are only three possible types of market equilibria:

Case A. No non-GM crops. $\quad \mathrm{q}_{\mathrm{n}}=0$.

Case B. $\quad$ No GM crops $\quad \mathrm{q}_{\mathrm{g}}=0$.

Case C. Not all land is cultivated. $\mathrm{q}_{\mathrm{g}}>0 ; \mathrm{q}_{\mathrm{n}}>0$. Between the GM and non-GM crops there is a distance of at least $\mathrm{d}$ which is uncultivated.

These cases do not always coincide with cases 1-4 outlined earlier. For instance, the conditions under which Case 4 holds, for instance can lead to any of the 3 cases A-C. To clarify matters, Table 2 sets out a summary of the relationship between the optimal pattern of consumption and possible market equilibria. As can be seen, in some cases, multiple 
equilibria are possible: it may be unprofitable for a producer to switch to GM production if all land is given over to non-GM, but at the same time if all land is used for GM, then entry by non-GM producers will be unprofitable.

Table 2 here.

In general, even if the profit margin on non-GM varieties far exceeds that on the GM variety, the GM crop can drive out the non-GM. The reason is quite simple: if a non-GM crop is grown within a distance $\mathrm{d}$ of the GM variety, the grower cannot capture the price premium attached to the non-GM variety however high that may be. In such a situation it is always more profitable to grow the GM crop, or possibly, to stop cultivation altogether.

\section{Model Robustness.}

These results are stark and negative in tone, so it is worth briefly considering their robustness (again concentrating on the central case). First, let us consider the cost advantage enjoyed by the GM producers. Suppose that some fraction, $\alpha$, of the land could sustain a nonGM crop grown at a unit cost lower than that for the GM crop. Since no consumer prefers the GM crop when it is available at the same price as its non-GM counterpart, the optimum always involves this entire fraction $\alpha$ being planted with the non-GM crop. However, on the remaining land the previous analysis applies. In other words, even if the optimum level of the non-GM crop exceeds $\alpha$ there is no market equilibrium in which more than $\alpha$ of the land is given over to the non-GM crop. Thus coexistence of the crops is possible, but the result is still generically inefficient.

Consider also the role of the shadow, d. Suppose instead of being forced to charge $\mathrm{pg}_{\mathrm{g}}$ $<\mathrm{p}_{\mathrm{n}}$ for the product grown in the shadow, the producer faces a discount that is proportional to the level of contamination. Given the simplistic nature of labelling laws this may seem 
unrealistic. More to the point, as long as the price received, $\mathrm{p}_{\mathrm{n}}$ ' is less than that available for the non-GM crop, while the costs are the same, then no market equilibrium with all land planted and both crops can exist. If it did, then $\mathrm{p}_{\mathrm{g}}-\mathrm{c}_{\mathrm{g}}=\mathrm{p}_{\mathrm{n}}-\mathrm{c}_{\mathrm{n}}$, but then a producer growing the non-GM crop in the shadow could improve profits by switching to the GM variant.

A third possibility is one of Coasean-style bargaining. Given that many market equilibria are inefficient there may be scope for bargaining between producers over what is grown on adjacent land. Clearly, if all producers can bargain collectively and costlessly, then an efficient outcome might result. Since a similar argument would apply to almost any problems of externalities, bargaining involving all producers is probably not a reasonable starting point, but there may be opportunities for bargaining between smaller sets of producers that can ameliorate the stark results of the proposition. Consider first a situation where a producer has one or two neighbours and the shadow of a GM crop covers exactly the neighbouring producer's land. ${ }^{3}$ Focus on an inefficient market outcome where $p_{g}-c_{g}<p_{n}-c_{n}$ and the case of a producer with a GM neighbour, both of whom take prices as given. In the absence of bargaining this producer will also plant the GM. However it may be able to negotiate a deal in which both it and the neighbour switch to non-GM. If this neighbour also has a GM neighbour then the switch will raise joint profits of the negotiating producers (and produce the scope for a bilateral deal) when

$$
\begin{aligned}
& 2\left(p_{g}-c_{g}\right)<p_{n}-c_{n}+p_{g}-c_{n} \text { or } \\
& \left(p_{g}-c_{g}\right)+1 / 2\left(p_{n}-p_{g}\right)<p_{n}-c_{n}
\end{aligned}
$$

Recall that if co-existence is optimal then efficiency requires $p_{g}-c_{g}=p_{n}-c_{n}$. Thus

\footnotetext{
${ }^{3}$ The easiest way to imagine this situation is to suppose for a moment that the available land is simply a linear strip, one farm wide and that all farms are of equal size.
} 
costless bilateral bargaining can possibly eliminate some of the inefficiency of the extreme outcome where non-GM is excluded from the market, but does not in general lead to the fully efficient outcome.

What happens if $m>2$ producers can engage in multilateral talks about simultaneously producing the non-GM crop? Provided only one of them has a GM neighbour outside the coalition, there are potential gains from bargaining amongst the $\mathrm{m}$ firms when:

$$
\left(p_{g}-c_{g}\right)+\left(p_{n}-p_{g}\right) / m<p_{n}-c_{n}
$$

Thus, in the limit, as $m \rightarrow \infty$, the efficient outcome is achievable. ${ }^{4}$

In the context of the two dimensional model, where most producers have neighbours on all sides and the shadow of a GM crop is the set of neighbours (as in Figure 1), the argument becomes more complicated, essentially because if one group of $\mathrm{m}^{2}$ adjacent firms switch to non-GM the shadow is linear in $\mathrm{m}$. Formally, if a square of $\mathrm{m}^{2}$ adjacent producers $(\mathrm{m} \geq 3)$, surrounded by GM contemplate a switch from GM to non-GM then their joint profits will rise when,

$$
\left(p_{g}-c_{g}\right)+4(m-1)\left(p_{n}-p_{g}\right) / m^{2}<p_{n}-c_{n}
$$

Again, therefore one can conclude that as $\mathrm{m} \rightarrow \infty$, the efficient outcome is achievable or conversely, the level of feasible multilateral bargaining sets a limit on the achievable level of efficiency. One can also conclude that in this particular example at least 9 producers must be involved for any joint gains to be achievable from bargaining. Further, though the minimum number of bargaining firms may be as small as 4, (if the producers are located in the corner of the production rectangle), simple bilateral bargaining can never produce gains to both parties

\footnotetext{
${ }^{4}$ As $\mathrm{m}$ becomes large it becomes less reasonable to take prices as given and unaffected by the decision of the coalition.
} 
in a context where all producers are initially GM. ${ }^{5}$

To sum up, the proposition is robust in the face of bargaining behaviour, provided that only bilateral bargaining is possible and if the shadow of a GM producer encompasses all the land of its neighbours. If it is feasible to have larger coalitions of producers then the extreme outcome described in the proposition may be modified: that is equilibria can exist with both GM and non-GM crops, but in general unless the maximum feasible bargaining coalition is large, the efficient outcome is not achievable.

\section{Some Simulations.}

The model of the previous section is essentially static. In addition, its simplicity hides the starkness of the main result that the market equilibrium may be radically different from the optimum even if the external effect is small. To illustrate the point that different patterns of planting can have strongly differing implications for external effects, this section provides some illustrative calculations of the impact of the introduction of transgenic crops in a highly stylised agricultural district, composed of equal-sized fields occupying a square territory of width and length $n$. There are therefore $n^{2}$ fields, each of which can be planted with either a

\footnotetext{
${ }^{5}$ This discussion has proceeded on the basis of a right to plant anything. If instead producers have a right to sell non-GM then it is worth thinking of the all non-GM outcome as the status quo and considering the gains from a firm switching to GM. The basic points of the story are then similar: 1) the bigger the feasible coalition of bargaining firms, the greater the gains in efficiency; 2) bilateral bargaining cannot produce gains because a single would-be producer of GM must negotiate with 8 neighbours (3 if it is in a corner) to purchase the right to plant
} GM. 
transgenic or non-transgenic variety. For any given total number of fields given over to the transgenic variety, I consider three patterns of planting. In the first case, 'externality minimizing', the allocation of the transgenic variety to fields is done so as to minimize the number of adjacent non-transgenically planted fields. In the second case, 'externality maximizing' the number of adjacent fields of non-transgenic crops is maximized. In the third case, 'random' the fields given over to the transgenic crop are chosen at random, with each field having an equal probability of being chosen. The second variant of the model maximizing the externality - may be seen as highly artificial, but it provides a useful benchmark. The first variant is the pattern which would be chosen by a social planner - it is optimal, given the number of fields dedicated to the transgenic crop. The third variety can be seen as the outcome when each farmer acts independently.

True patterns of planting will typically fall somewhere between the first and third variants. The planting of varieties is often geographically concentrated because of underlying correlations of soil types and local weather conditions between farms. In addition, informal and formal information transmission mechanisms between farmers, plus variations in the dominant local supplier of farming inputs, and in the sites of food processors, all lead to clusters in patterns of planting. Against this, risk management practices by farmers and individual preferences tend to lower local concentration. As a result the random model may be a useful first approximation to actual patterns of land use.

I proceed as follows. For $n=20$ I calculate the pattern of GM planting which minimizes and maximizes the externality effect, assuming that the external effect is confined to the adjacent fields. Thus for 1 transgenically-planted field in the centre of the square, another eight fields are affected. In fact for $n=20$, with only 49 fields planted transgenically all other fields can be adjacent to a transgenically-planted field. For the random planting, I 
draw sequences of 50 random numbers from the set $\{1, \ldots, 400\}$. Each number then represents a field given over to the transgenic crops. The number of adjacent fields affected is then calculated.

Figure 1 shows some illustrative patterns of the spatial externality (for $n=9$ rather than the value of $\mathrm{n}$ used in the actual simulations). In the figure, black-shaded squares represent fields planted with transgenic crops. The diagonally-shaded squares then represent the fields in the shadow of the transgenically-planted fields.

\section{[Figure 1 about here]}

As an alternative method, some approximate theoretical calculations can be used to predict the effect of random planting. Suppose that (t-1) randomly selected fields have been denoted transgenic and that as a result, a proportion $\pi$ of the total area is affected by the transgenically-planted fields ( $\pi$ includes those fields actually planted with the transgenic varieties plus their shadow). Then the probability that the next randomly selected field (the $\mathrm{t}^{\text {th }}$ ) lies in the shadow is approximately $\pi$ and the probability it lies outside of the shadow is approximately $(1-\pi)$. If it does lie in the shadow then no new fields are added to the shadow. On the other hand if the $\mathrm{t}^{\text {th }}$ field lies outside of the shadow, then for $\mathrm{n}=20$, the expected number of fields in the shadow plus the field itself is $8.41 .^{6}$ It follows that an approximate differential equation governing $\pi$ is,

\footnotetext{
${ }^{6}$ Note that this number allows for the fact that transgenic fields near the corners or one edge of the territory have a smaller shadow than fields away from the edges. Formally in a nxn area, there are $(n-1) x(n-1)$ fields with a shadow of 9. The remaining (2n-1) fields that line the perimeter each have a shadow of 3 . Thus the expected shadow of a randomly selected field is $9-6(2 n-1) / n^{2}$
} 


$$
\frac{d \pi}{d t}=8.41(1-\pi) / 400
$$

Solving this equation yields the formula:

$$
\pi=1-e^{-\frac{8.41 t}{400}}
$$

Of course this formula is approximate. In practice the $\mathrm{t}^{\text {th }}$ field may not lie in the shadow of an existing transgenic field, but it may lie adjacent to the shadow in which case the number of new fields added to the shadow will be smaller than that predicted by the theory. Additionally, the formula becomes nonsensical for large values of $t$, because with $t=400$ all fields must be transgenically planted. However, for low levels of GM planting it works well, as figure 2 illustrates. There, in addition to curves depicting the consequences of the externality maximizing and minimizing patterns of planting, figure 2 plots two curves, one of which is the mean from the randomly generated sets of transgenically-planted fields ('mean') and one of which is equation (9) ('theory'). In fact this equation explains over $99 \%$ of the variation in the data generated by the random numbers method.

\section{[Figure 2 about here]}

The results in figure 2 suggest that if transgenic crops occupy only $10 \%$ of the area, then over $60 \%$ of the total area could be denied to non-transgenic crops though the spatial externality is only one field in extent. ${ }^{7}$ Although the details should perhaps not be taken too

\footnotetext{
${ }^{7}$ Further simulations were carried out with larger potential shadows and larger values of $n$. Typically, with a shadow extending to two field widths, less than $10 \%$ of the area was available to non-GM crops when only $10 \%$ of the area was randomly planted with transgenic varieties. With three field widths only a fraction of the territory remained outside of the shadow.
} 
seriously, figure 2 does illustrate some important principles. First, the area potentially affected in two dimensions is proportional to the square of the area planted and is therefore not linear. Second, most crucially for policy purposes, the different patterns of planting can have widely differing patterns of impact. The area unavailable for non-GM varieties with random planting is up to 3.7 times the area unavailable under the externality minimizing solution.

Some work on the dynamics of planting was also carried out. I use a baseline model in which the GM crops have a cost advantage of $10 \%$, three percent of the population are indifferent between GM and non-GM $(\theta=0), 65 \%$ would refuse to take the GM at any positive price $(\theta=a)$, and the remainder have values of $\theta$ uniformly distributed on $(0, a)$. This particular configuration of parameters yields an initial market share of 5\% for the GM variety in the first period. About one third of all the land area is then unavailable for the non-GM crop. Consequently, in the next period the profitability of the GM crop falls to zero. Assume that the fields newly planted with the GM variety in the second period are adjacent to those used for the GM crops in the first period. An equilibrium is reached in which approximately $6 \%$ of the land is used for GM, $61 \%$ is used for the non-GM crop and a further $33 \%$ in the shadow of the GM crop remains uncultivated. Changes to the parameters around the initial values (e.g. using consumer preference figures similar to the results of Noussair et al, 2004 or Matsumoto, 2006 for consumers in Japan), yield very similar results, principally because the shadow of the planted area is so large compared to the area of transgenic crops. Also because prior to the introduction of the GM crop all land is used for non-GM production, these results represent a relatively high cost from the launch of the GM variety (approximately $19 \%$ of the total initial surplus) so it is worthwhile stressing the assumptions made of random planting and the absence of natural or man-made barriers in the landscape. Both of these factors would 
potentially limit the spatial externality. ${ }^{8}$

\section{Policy Options.}

In discussing the robustness of the proposition we have already seen the possibilities of Coasean bargaining and also the limitations. In this section, I consider other possible interventions in the market equilibrium, designed to maximize the total surplus which in turn implies efficiency in consumption and efficiency in production. The latter means minimizing the total costs of producing aggregate consumption levels $\left(\mathrm{q}^{*}{ }_{\mathrm{n}}, \mathrm{q}_{\mathrm{g}}{ }_{\mathrm{g}}\right)$. Given a GM-affected area of $\delta$, this implies total costs $=\mathrm{c}_{\mathrm{n}}\left(\mathrm{q}^{*}{ }_{\mathrm{n}}+\delta\right)+\mathrm{c}_{\mathrm{g}}\left(\mathrm{q}_{\mathrm{g}}{ }_{\mathrm{g}}-\delta\right)$. So minimizing production costs given the aggregate consumption level also means minimizing $\delta$ and thus it follows that production efficiency is also externality minimizing. The main conclusion from this section is that achieving consumption efficiency is relatively straightforward, but that production efficiency is more problematic.

To create consumption efficiency there has to be some incentive for farmers to sow the non-GM crop when they lie in the shadow of GM crops. In this way the crops can co-exist in a market equilibrium. For a non-GM farmer, the effect of being in a region affected by GM crops is to lower the price received per unit from $p_{n}$ to $p_{g}$. Hence one Pigouvian instrument is

\footnotetext{
${ }^{8}$ The results on the rapid spread of the GM contaminated land deviate somewhat from Belcher et al, 2005. The big differences are that I incorporate consumer demand (that slows the spread) and allow the possibility of unused land. These two elements help promote coexistence.
} 
a per unit subsidy, $\mathrm{s}$, on the non-GM crop of $\mathrm{s}=\Delta \mathrm{p}^{9}$.

In this context, consider a market equilibrium in which aggregate consumption is $\left(\mathrm{q}^{*}, \mathrm{q}^{*} \mathrm{~g}\right)$ - i.e. at its optimum levels. From equations (2)-(7) we know that equilibrium consumer prices are such that $p_{g}-c_{g}=p_{n}-c_{n} \geq 0$. Thus farmers growing the non-GM crop and selling it as such receive profits per unit of $\Delta p+p_{n}-c_{n}$. Hence they have no incentive to switch crops. Any farmer growing GM crops and completely surrounded by non-GM farms would have an incentive to switch crops, so this particular pattern cannot be part of an equilibrium. However, any producer growing GM and lying within the shadow of another GM producer would receive $\mathrm{p}_{\mathrm{g}}-\mathrm{c}_{\mathrm{n}}+\Delta \mathrm{p}=\mathrm{p}_{\mathrm{n}}-\mathrm{c}_{\mathrm{n}}=\mathrm{p}_{\mathrm{g}}-\mathrm{c}_{\mathrm{g}}$ from switching and therefore has no incentive to do so. Finally, for a non-GM producer in a GM-affected area the per unit profits from planting non-GM are $p_{g}-c_{n}+p_{n}-p_{g}=p_{n}-c_{n}$, compared to $p_{g}-c_{g}$ obtainable from planting the GM crop. Hence again there is no incentive to switch. So, there exists a market equilibrium in which $\mathrm{p}_{\mathrm{n}}{ }^{-}$ $\mathrm{c}_{\mathrm{n}}=\mathrm{p}_{\mathrm{g}}-\mathrm{c}_{\mathrm{g}}$, aggregate consumption levels of the two products are $\left(\mathrm{q}^{*}, \mathrm{q}^{*} \mathrm{~g}\right)$, all land is cultivated. ${ }^{10}$ Moreover, on the consumption side this equilibrium is unique.

To see this suppose not and consider first the case of some other prices $\mathrm{p}_{\mathrm{n}}, \mathrm{p}_{\mathrm{g}} \mathrm{g}_{\mathrm{w}}$ which do not satisfy $p^{\prime}{ }_{n}-c_{n}=p^{\prime}{ }_{g}-c_{g}$. If $p^{\prime}{ }_{n}-c_{n}>p^{\prime}{ }_{g}-c_{g}$, then a GM farmer can make more profit by

${ }^{9}$ Although I analyse a subsidy for the non-GM crop the lessons of this section apply equally to a unit tax of $\Delta \mathrm{p}$ on GM crops. A subsidy of $\Delta \mathrm{p}$ on non-GM crops is largely wasted in the sense that in the market equilibrium, most of the subsidy is paid to intra-marginal farmers. Hence a cheaper and equally effective instrument is a subsidy paid only to farmers planting in the shadow of GM crops.

${ }^{10}$ And no GM producer is isolated, in the sense of being outside the shadow of any other GM producer. 
switching to producing the non-GM crop. Hence $\mathrm{p}^{\prime}{ }_{n}-\mathrm{c}_{\mathrm{n}}>\mathrm{p}_{\mathrm{g}}{ }_{\mathrm{g}}-\mathrm{c}_{\mathrm{g}}$ cannot be a market equilibrium. If $\mathrm{p}^{\prime}{ }_{\mathrm{n}}-\mathrm{c}_{\mathrm{n}}<\mathrm{p}_{\mathrm{g}}{ }_{\mathrm{g}}-\mathrm{c}_{\mathrm{g}}$, then a non-GM farmer can make more profit by switching to the GM crop. So in any equilibrium the prices must satisfy $p^{\prime}{ }_{n}-c_{n}=p^{\prime}{ }_{g}-c_{g}$. If these other prices were higher, then total demand would be lower and so some land would be uncultivated, but then given the profitability of production, some farmer would wish to produce on the uncultivated land. So, suppose the other prices were lower, then there would be excess demand for one or both products - implying that feature (a) of a market equilibrium was not satisfied.

As intimated above, the issue of production efficiency is more problematic. Although a subsidy of $\Delta \mathrm{p}$ on the non-GM crop yields an outcome which is unique for consumption, there is typically a non-unique solution to the planting decision. Figure 3 illustrates the problem. In this diagram, shaded cells represent the non-GM crop, cells with diagonal stripes represent the non-GM crop which is viewed by consumers as GM because it is planted in the shadow of the GM crop and unshaded cells represent the GM crop. As can be seen, in both parts of the figure the total production of the non-GM crop that is sold to consumers as nonGM is the same. Likewise the total area sold as GM is the same. However, the configuration of crops in $3 \mathrm{a}$ is production efficient because it minimizes the area of crops sown as non-GM and sold as GM. If $\mathrm{s}=\Delta \mathrm{p}$ then both configurations represent a market equilibrium. It is readily seen therefore, that using a per-unit subsidy is compatible with a pattern of planting which is highly inefficient, in the sense of maximizing the area of non-GM affected by GM crops given the constraint that aggregate consumption equal $\left(\mathrm{q}^{*}, \mathrm{q}_{\mathrm{g}}{ }_{\mathrm{g}}\right)$. The same holds true for any instrument that does not give incentives for crop types to cluster. ${ }^{11}$

${ }^{11}$ We have already had a discussion of the difficulty of bilateral bargaining to achieve 


\section{[Figure 3 about here]}

One instrument that does produce clustering incentives is a per unit subsidy on the non-GM crop equal to $\Delta \mathrm{p}\left[\delta / \delta^{*}\left(\mathrm{q}_{\mathrm{n}}, \mathrm{q}_{\mathrm{g}}\right)\right]$. Since $\delta=\delta^{*}$ at the social optimum, then the social optimum is a market equilibrium. Moreover it is the only market equilibrium consistent with consumption efficiency. ${ }^{12}$ However, there will typically be other market equilibria which are neither production efficient nor consumption efficient. To see this, note that the market equilibrium condition for producers is $\Delta \mathrm{p} \delta / \delta^{*}=\mathrm{c}_{\mathrm{n}}-\mathrm{c}_{\mathrm{g}}$. If this holds then no GM producer can gain from switching to non-GM production and no non-GM producer can gain from switching to GM production. However, consider any production efficient pattern of planting such $\Delta \mathrm{p}<\mathrm{c}_{\mathrm{n}}-\mathrm{c}_{\mathrm{g}}$ (so that the consumption of non-GM crop exceeds its optimum value). Now, into the GM zones imagine introducing isolated patches of the non-GM crop so that all the patches of non-GM lie in the shadow of GM crop. As a result the consumer prices of GM and non-GM are unchanged, but $\delta$ exceeds $\delta^{*}$. Continue with this procedure until $\Delta \mathrm{p} \delta / \delta^{*}=\mathrm{c}_{\mathrm{n}}-\mathrm{c}_{\mathrm{g}}$ and we have a market equilibrium, but one which is consumption inefficient.

These alternative market equilibria are not all stable, in the sense that for some small changes in land-use, there can be no incentive for decentralised planting decisions to reinstall the original equilibrium. To see this, consider a switch of production of some infinitesimal unit of land from GM crops to non-GM. Three cases are possible. First the unit of land may

efficiency, but it is also worth noting that the problem represented by Figure $3 b$ is not solved by allowing bilateral bargaining.

${ }^{12}$ It does though suffer from some clear disadvantages in that, unlike the simpler instrument discussed previously, the value of the subsidy requires calculations of $\delta$ which in turn may require extensive information on planting patterns. 
be added to the shadow, in which case $\delta$ would rise. Meanwhile the total quantity of each type of crop reaching consumers would be unchanged, so consumer prices would be unchanged. This would lower the profitability of GM relative to non-GM grown in the shadow, encouraging more farms to switch from GM to non-GM.

In the second case, suppose the unit of land lies outside the shadow of other GM farms, so that its produce can be sold as non-GM. Since this yields greater profits than GM at the market equilibrium, then the alternative market equilibria are not stable in the face of perturbations of this kind. Finally, the conversion could release some other plot of land from the shadow, but be in the shadow itself. The net effect would be that the quantity of non-GM crop reaching consumers would rise. As a result, GM crops would become relatively more profitable compared to non-GM crops grown in the shadow encouraging the unit of land to be converted back to GM. Thus unlike the first two cases, in the face of this kind of perturbation the equilibrium is stable.

It is also true that the market equilibrium where $\mathrm{s}=\Delta \mathrm{p}\left[\delta / \delta^{*}\left(\mathrm{q}_{\mathrm{n}}, \mathrm{q}_{\mathrm{g}}\right)\right]$ and $\delta=\delta^{*}\left(\mathrm{q}_{\mathrm{n}}, \mathrm{q}_{\mathrm{g}}\right)$ is also not stable in the face of some perturbations: if a unit of land used for growing GM crops is switched to non-GM at the social optimum then $\delta$ rises, raising an incentive for other GM farms to switch varieties.

Summing up, market-based instruments are relatively easy to implement if the goal is purely one of consumption efficiency, but the equilibria may be non-unique and not stable. As a result, assuring production efficiency is problematic. So, finally, let us briefly investigate policies which mix market-based incentives with planting regulations.

Obviously one way to achieve optimality is to specify the land which is to be devoted to each crop. This encounters the familiar Hayekian issue that that planner must know consumer preferences if the optimal allocation of land is to be made, but typically preferences 
are not known with this precision. A relatively straightforward way to overcome the problem is to mix a unit subsidy with a licensing scheme for crops. Any grower may apply for a license to grow GM crops. Such a license will only be approved however, when the resulting pattern of land use is externality-minimizing. If the subsidy for non-GM crops is set at $\Delta \mathrm{p}$ then demand for the license will be up to the point at which $\Delta \mathrm{p}=\mathrm{c}_{\mathrm{n}}-\mathrm{c}_{\mathrm{g}}$. In this way both consumption and production efficiency may be achievable.

\section{Discussion.}

This paper has examined the problem of spatial contamination by transgenic crops. Its essential lesson is that efficiency is unlikely to obtain without regulation and that in some circumstances co-existence between GM and non-GM varieties may be unsustainable in an unregulated market. As a result policy interventions were considered. The necessity of these policy instruments obviously rests on the assumption of an external effect flowing from the introduction of transgenic crops, but it also rests on the uninterrupted spread of the externality. To the extent that natural physical barriers, intervening crops, cities, etc. separate groups of farms growing the same crop into isolated islands of production, it is possible that a rough approximation to optimality can be achieved without extensive regulation. However, note that as long as there is no cost to the GM-planting farmer from introducing a transgenic crop into a previously GM-free geographical area, then equilibrium between GM and non-GM cultivars is inherently unstable.

The feasibility of the instruments depends in part on the size of the barrier which must be maintained in order to avoid cross-contamination between transgenic and non-transgenic cultivars. Although physical barriers such as hedges and woodland can reduce the flow of dispersing pollen, the conclusion of the Treu and Emberlin survey was that such features 
diluted rather than contained the flow. Meanwhile safe distances are potentially large, to go by the UK Soil Association's decision to define a circle of radius 6 miles $(9.6 \mathrm{~km})$ from a planted crop to the nearest field of its transgenic relative, within which it would reserve the right to label a crop 'non-organic'. For non-organic, non-transgenic crops, the requirements will ultimately be determined by consumer preferences and may not be so large. National regulators (see Table 1) have set much smaller distances, but even they are of the order of a field-width, which as we have seen above can imply large areas affected by GM crops.

A final important issue which is not captured in the model is the important issue of irreversibility. For transgenic oilseed rape, Norris et al, 1999, found viable seed in the soil persisted for up to 3 years after the initial planting of the crop. In its list of qualifying regulations for organic crops, the UK's Soil Association will not accept crops grown on land where transgenic crops have been grown within the last five years. Irreversibility does not alter the equilibrium analysis presented in section 2 . However it affects the feasibility of certain paths to equilibrium. In particular, it may be problematic to approach the social optimum from a situation where the GM crop is grown beyond its optimal extent or where its planting has been poorly co-ordinated. 


\section{References.}

Aslaksen, I. and Myhr, A. Ingeborg, 2007, 'The worth of a wildflower": Precautionary perspectives on the environmental risk of GMOs : Short survey Ecological Economics, Volume 60, Issue 3, 1 489-497

Batie S., 2003, The Environmental Impacts of Genetically Modified Plants: Challenges to Decision Making, American Journal of Agricultural Economics, v. 85, 1107-1111.

Belcher, K., J. Nolan and P. W. B. Phillips, 2005, Genetically modified crops and agricultural landscapes: spatial patterns of contamination, Ecological Economics Volume 53, Issue 3, 387-401.

Bock, A.K., Lheureux, K., Libeau-Dulos, M., et al., 2002. Scenarios for co-existence of genetically modified, conventional and organic crops in European agriculture, Institute for Prospective Technological Studies and Joint Research Centre of the European Commission IPTS-JRC. Sevilla.

Carpenter, J. and L. Gianessi, 1999, Herbicide Tolerant Soybeans: Why Growers are Adopting Roundup Ready Varieties, 2(2) Spring, 65-72.

Commission of the European Communities, 2006, Report on the implementation of national measures on the co-existence of genetically modified crops with conventional and organic farming (Annexe). http://ec.europa.eu/agriculture/coexistence/sec313_en.pdf

Department of the Environment Transport and the Regions, 1999, Environmental Risks of Herbicide-Tolerant Oilseed Rape: A Review of the PGS Hybrid Oilseed Rape

Fulton, M., Giannakas, K., 2004, Inserting GM products into the food chain: The market and welfare effects of different labelling and regulatory regimes, American Journal of Agricultural Economics, 86:42-60. 
Guardian, 2000, Farmer Puzzled by Weed Killer's Surprise Crop, February 02, page 4.

Goeschl, T. and T. Swanson, 2003, The development impact of genetic use restriction technologies: a forecast based on the hybrid crop experience. Environment and Development Economics 8: 149-165.

Matsumoto, S., 2006, Consumers' Valuation of GMO Segregation Programs in Japan Journal of Agricultural and Applied Economics, April , 38, 201-210.

Mikkelsen, T. R., Andersen B and R. B. Jorgensen, 1996, The risk of transgene spread, Nature, 380, 31.

Munro, A., 1997, Economics and Biological Evolution, Environmental and Resource Economics, 9: 429-449.

Munro, A., 2000, The Regulation of Genetically Modified Crops, presented at "Biotechnology, Environmental Policy, and Agriculture: A workshop on the management of the impacts of biotechnologies", Rome, Italy - 28-30 May 2000

Munro, A, 2003, Monopolisation and The Regulation of Genetically Modified Crops: An Economic Model, Environment and Development Economics 8: 167-186.

Nelson, G. C., Bullock, D.S., 2003, Simulating a relative environmental effect of glyphosate- resistant soybeans, Ecological Economics, 45: 189-202 .

Norris, C. E., Simpson, E. C., Sweet, J. B. and J. E. Thompson, 1999, Monitoring weediness and persistence of genetically modified oilseed rape (Brassica napus) in the UK. In: Lutman, P. J. W. (Ed.), Gene Flow and Agriculture: Relevance for Transgenic Crops, British Crop Protection Society Symposium Proceedings no. 72.

Noussair, C., Robin, S., and Ruffieux, B., 2004, Do Consumers Really Refuse To Buy Genetically Modified Food?, Economic Journal, 114 (January), 102-120.

Scheffler, J., and P. Dale, 1994, Opportunities for gene transfer from transgenic oilseed rape $-28-$ 
(Brassica napus) to related species. Transgenic Research 3(5), 263-278.

Sianesi, B. and D. Ulph, 1998, Species Loss Through the Genetic Modification of Crops -A Policy Framework, mimeo, University College London.

Soil Association, 1999, Standards for Organic Food and Farming: Genetic Engineering, Soil Association.

Treu, R. and J. Emberlin, 2000, Pollen Dispersal in the crops Maize, Oil seed rape, Potatoes, Sugar Beet and Wheat: Evidence from Publications, Report for the Soil Association. 
Table 1. The Range of Officially Recommended minimum separation distances for GM Crops in the European Union

\begin{tabular}{|l|l|l|}
\hline Crop & Maximum (metres) & Minimum (metres) \\
\hline Maize & $800 \mathrm{~m}$ (Luxembourg) & $25 \mathrm{~m}$ (Netherlands) \\
\hline Maize (organic crop) & $800 \mathrm{~m}$ (Hungary) & $50 \mathrm{~m}$ (Spain) \\
\hline Maize (certified seed crop) & $800 \mathrm{~m}$ (Hungary) & $200 \mathrm{~m}$ (Denmark) \\
\hline Potato (organic) & $20 \mathrm{~m}$ (Denmark) & $2 \mathrm{~m}$ (Sweden) \\
\hline Beet (organic) & $2000 \mathrm{~m}$ (Portugal) & $3 \mathrm{~m}$ (Netherlands) \\
\hline
\end{tabular}

Source(s): Table 3, Commission of the European Communities, 2006. Note that as of 2007 not all EU member states have settled on official minimum distances. 
Table 2. Optimality and Possible Market Equilibria.

\begin{tabular}{|c|c|c|c|}
\hline Market & Case A & Case B & Case C \\
\hline Equilibrium $\rightarrow$ & $\mathrm{q}_{\mathrm{n}}=0$ & $\mathrm{q}_{\mathrm{g}}=0$ & $\mathrm{q}_{\mathrm{n}}+\mathrm{q}_{\mathrm{g}} \leq 1-\mathrm{wd}$ \\
\hline Social optimality $\downarrow$ & & & $\mathrm{q}_{\mathrm{n}}>0 ; \mathrm{q}_{\mathrm{g}}>0$ \\
\hline Case 1. & If $\mathrm{qg}_{\mathrm{g}}{ }^{* *} \geq 1-\mathrm{wd}$ or if & & If $\mathrm{qg}^{* *}<1-\mathrm{wd}$ \\
\hline $\mathrm{q}_{\mathrm{n}}+\mathrm{q}_{\mathrm{g}}=1 ; \mathrm{q}_{\mathrm{n}}>0 ; \mathrm{q}_{\mathrm{g}}>0$ & $\begin{array}{c}\text { shadow covers all } \\
\text { land. }\end{array}$ & Not Possible & \\
\hline Case 2 & If shadow covers all & & If $\mathrm{qg}^{* *}<1-\mathrm{wd}$ \\
\hline $\mathrm{q}_{\mathrm{n}}+\mathrm{q}_{\mathrm{g}} \leq 1 ; \mathrm{q}_{\mathrm{n}}>0 ; \mathrm{q}_{\mathrm{g}}>0$ & land & Not Possible & \\
\hline Case 3 & & & \\
\hline $\mathrm{q}_{\mathrm{g}}=1$ & Possible & Not possible & Not Possible \\
\hline Case 4 & & & \\
\hline $\mathrm{q}_{\mathrm{n}}=1$ & If $\theta^{\mathrm{L}} \leq \mathrm{a}-\mathrm{c}_{\mathrm{g}}$ & Possible & If $\mathrm{qg}^{* *}<1-\mathrm{wd}$ \\
\hline
\end{tabular}

\section{Notes:}

1. 'Possible' means that the market equilibrium is a possible outcome given the conditions under which Case $\mathrm{i}, \mathrm{i}=1, \ldots, 4$ pertains without further restrictions on the parameters.

2. $\mathrm{q}_{\mathrm{g}} * *=$ demand for GM crop when $\mathrm{p}_{\mathrm{n}}=\mathrm{a}$ and $\mathrm{p}_{\mathrm{g}}=\mathrm{c}_{\mathrm{g}}$. That is the maximum demand for the GM crop possibly compatible with a market equilibrium.

3. If $\theta^{\mathrm{L}} \leq \mathrm{a}-\mathrm{c}_{\mathrm{g}}$ is satisfied then production of the GM crop is profitable in the absence of the non-GM product. 


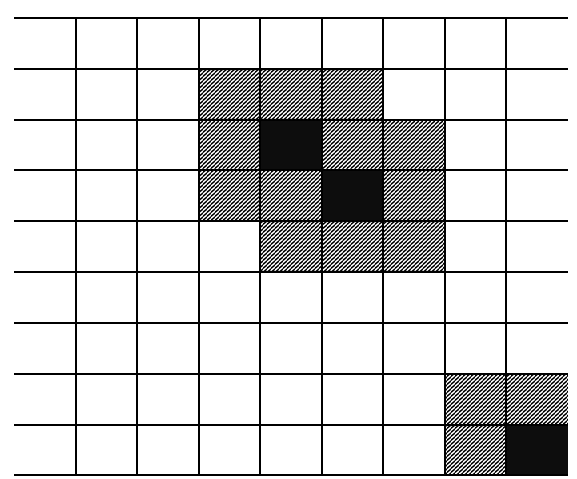

Figure 1. Illustrative Patterns

of the GM Spatial Externality. 


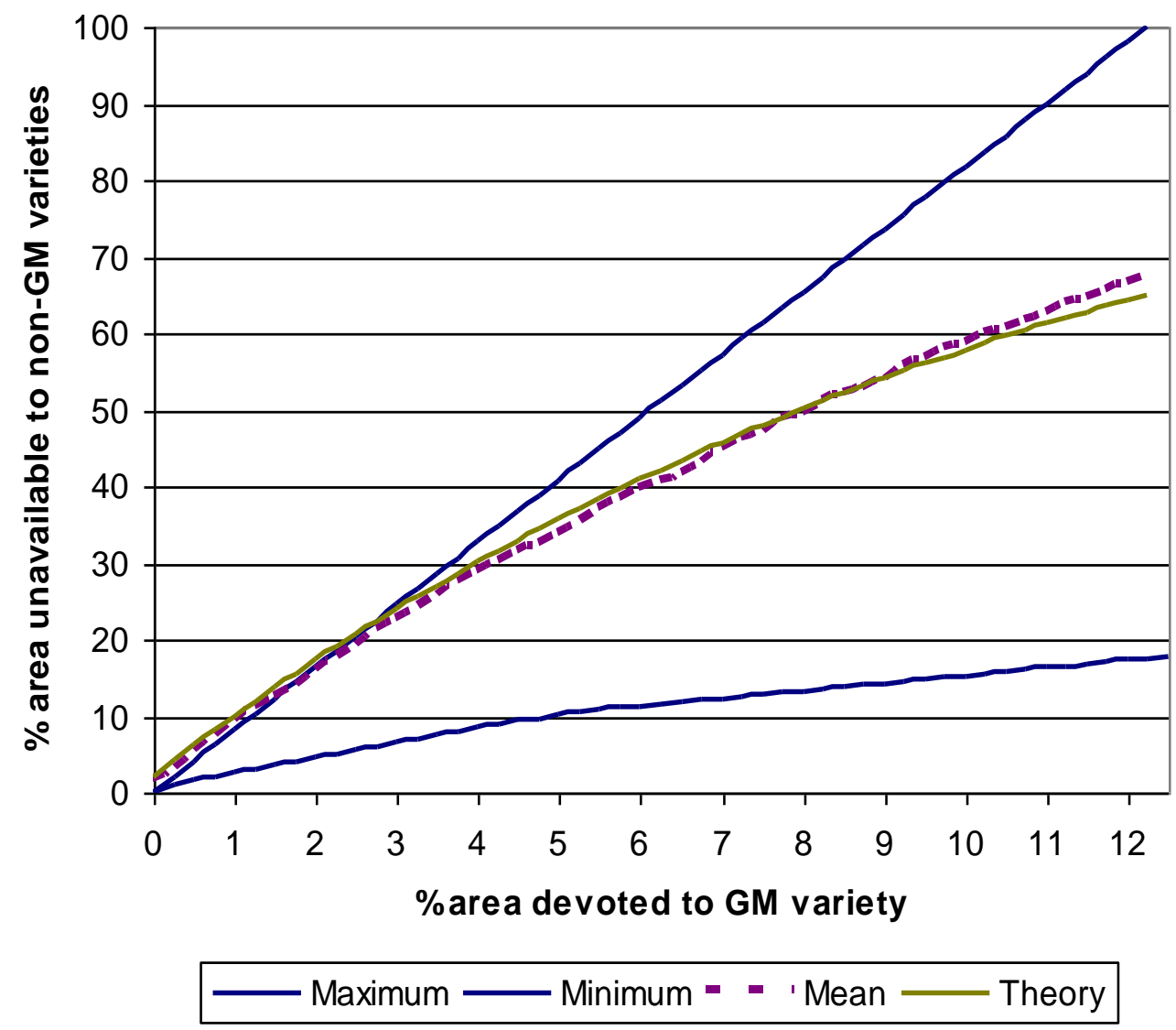

Figure 2. The relationship between area planted with GM variety and the area unavailable to non-GM varieties. 


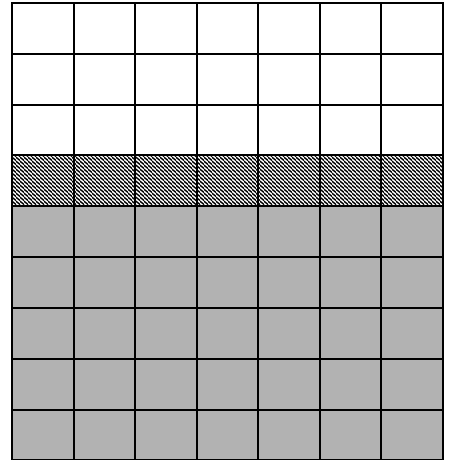

Figure 3a. One boundary, production efficiency.

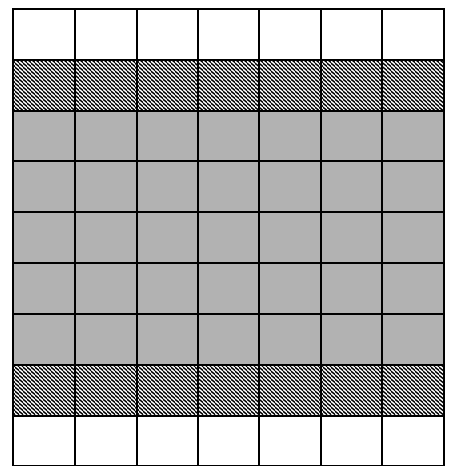

Figure 3b. Two boundaries, production inefficiency.

Note: Shaded area $=$ non-GM crop sold as non-GM. Diagonally shaded $=$ non-GM crop sold as GM. Unshaded area $=$ GM crop. 